Article

\title{
Determination of the Surface and Canopy Urban Heat Island in Athens Central Zone Using Advanced Monitoring
}

\author{
Chrissa Georgakis ${ }^{1, *}$ and Mattheos Santamouris ${ }^{2}$ \\ 1 Group of Building Environmental Physics, University of Athens, Building Physics 5, University Campus, \\ 15784 Athens, Greece \\ 2 The Anita Lawrence Chair in High Performance Architecture, School of Built Environment, \\ University of New South Wales, Sydney, NSW 2052, Australia; m.santamouris@unsw.edu.au \\ * Correspondence: cgeorgakis@phys.uoa.gr; Tel.: +30-210-7276870
}

Received: 7 November 2017; Accepted: 14 December 2017; Published: 20 December 2017

\begin{abstract}
The present study aims to present all the findings of micro-climate measurements that were performed by the University of Athens in the center of Athens, during the summer period. The extended experimental campaign aimed to collect thermal and air flow measurements, in different measuring points along a main street in the city center, in order to estimate the surface and canopy heat island intensity. In this work, the methodology of collecting the data, the experimental procedure, the equipment used, and lastly, the results are being presented. Comparison with the meteorological conditions that are recorded in the National Observatory of Athens, for the same period, lead to important conclusions about the local microclimate in the center of Athens and specifically the magnitude of the heat island effect. Particularly, in the denser area of the city after midday, air temperature increases reaching values up to 5 degrees higher than the one recorded in the suburban area. On the contrary, early in the morning the air temperature of the "green area" of the city was found to be lower up to 2 degrees than the corresponding in the suburban area.
\end{abstract}

Keywords: urbanization; air and surface temperature measurements; outdoor thermal comfort; urban heat island; surface cool island effect

\section{Introduction}

\subsection{The UHI and Its Intensity Impact}

The urban heat island (UHI) is the most studied phenomenon relative to increased urbanization. Air temperatures in the densely built area are higher when compared to the ones in the surrounding sub-urban areas due to positive urban thermal balance. The maximum differences between urban air temperatures and the background rural or suburban temperatures define the UHI magnitude [1]. There are several parameters influencing the intensity of the urban heat island. These are the urban characteristics (size and population of the city), the local meteorological features, the topography, the type of urban materials, and the presence (or lack) of green areas [2]. Several studies around Europe and the United States (US) have been performed estimating the increased air temperature in the urban fabric [2-4].

The effect of UHI is well known in Athens, the capital city of Greece, a city with a population explosion during the last decades. Primary studies conducted in order to estimate the heat island effect in Athens, used data from routine standard fixed meteorological stations. Time series of the air temperature data recorded in routine standard fixed urban and rural meteorological stations around the Athens basin, for the period 1961-1982, were used in a study about UHI. The minimum mean 
monthly air temperature's differences between the urban and rural stations indicated that, the UHI intensity was up to $3^{\circ} \mathrm{C}$ during that period [5].

Meso-scale and synoptic data covering the period 1990-2001 were analysed in order to estimate UHI [6]. The urban heat island was estimated using the minimum temperature differences between rural and urban areas of the city of Athens, in the morning. The UHI was detected in the $2 / 3$ of the examined period, being strong enough for the $1 / 3$ of these days, yearly. During this $1 / 3$ of the days annually, the strength of the UHI was more than $3^{\circ} \mathrm{C}$ [6].

Intelligent 'data-driven' methods have been used to assess the magnitude of the urban heat island phenomenon. Hourly ambient air temperature values, which were recorded at twenty-three stations in the Athens region, have been 'data-driven' analysed. It was found that the heat island intensity follows both periodic and non-periodic fluctuations, depending on the weather conditions, as well as on topographic and topoclimatic complexities and synoptic flow patterns. It was estimated that the mean seasonal values of the UHI for the fifteen most central urban stations around Athens, were close to $5.4{ }^{\circ} \mathrm{C}$ for summer, $3.2{ }^{\circ} \mathrm{C}$ for autumn, $2.1^{\circ} \mathrm{C}$ for winter, and $3.1{ }^{\circ} \mathrm{C}$ for spring [7].

An extended experimental study about the urban heat island magnitude in Athens basin, conducted in thirty urban and suburban monitoring stations. The results were based on maximum air temperature differences between measurements of the most central urban stations to the rural ones. It was estimated that the heat island intensity for the city of Athens was up to $10{ }^{\circ} \mathrm{C}$ during daytime and $5{ }^{\circ} \mathrm{C}$ during night [8]. Measurements have been used to assess the impact of the urban climate on the energy consumption of buildings. The impact of the urban heat island to the microclimatic conditions is of great interest and increases the need for cooling. It was estimated that monthly cooling load in the dense built urban area is around 120\% higher, while the heating load is around $38 \%$ lower when compared to the reference suburban areas [8].

Urban heat island phenomenon may occur during nighttime period, as a function of the local thermal balance, resulting from the delayed cooling of the city, in comparison to the temperatures in the surrounding rural areas. Measurements of air temperature have been carried out, within three deep urban canyons of different aspect ratios, during nighttime [9]. Under clear and calm climatic conditions, the variation of the median heat island intensity was found to be between $2.2^{\circ} \mathrm{C}$ to $2.7^{\circ} \mathrm{C}$.

In the microclimatic analysis that was carried out in a medium size sub-urban city area, Acharnes, $10 \mathrm{~km}$ north of the center of Athens, heat island intensity was found to be strongly connected to the thermal properties of the materials used as coatings in the urban fabric [10]. Air temperature varied from $22.3^{\circ} \mathrm{C}$ up to $32.3^{\circ} \mathrm{C}$ in the streets of the studied areas, significantly high values when considering the measuring period (April-May). The thermal properties of the materials that were used as coatings in the studied areas were of low albedo and high thermal capacity. The daily average surface temperatures of the materials that were used in the urban fabric, varied between $37.4^{\circ} \mathrm{C}$ for the pavements and $41.8^{\circ} \mathrm{C}$ for the asphalt.

\subsection{Advanced Mitigation Techniques}

Nowadays, in order to counterbalance the urban heat island effects, several efficiency techniques have been proposed and assessed in a considerable amount of studies. Advanced mitigation techniques could possibly lead to a proportionate reduction in degrees of the peak ambient summer temperature. Urban regeneration leads to the sustainable development of the urban fabric through the rehabilitation of the existing urban fabric and the preservation of green spaces. Use of cool materials in paths, roads, and building rooftops in order to highly reflect solar radiation, together with a high emissivity factor can significantly contribute to the reduction of surface temperatures up to several degrees. Cool communities' strategies reroof and repave in lighter colors and cool materials in order to reduce air temperature in cities and reduce the increased heat island effect [11-13].

In the Maroussi area, a densely built neighborhood in Athens, detailed simulation techniques have permitted the evaluation of the rehabilitation of the area. Cool materials have been proposed as coatings for pavements and streets; the amount of green spaces was increased. Solar control 
devices and earth to air heat exchangers were implemented in the simulation. Computational analysis indicated a decrease of the peak ambient temperature in the built area up to $3.4{ }^{\circ} \mathrm{C}$ under peak summer conditions. The application of all the above techniques may decrease the surface temperature and improve the thermal comfort conditions [14].

Recently, one of the largest urban mitigation projects in Greece provided information about the rehabilitation of an urban area with increased ambient temperature during the last decay [15]. In a major traffic axis of Western Athens, covering a total zone of $37,000 \mathrm{~m}^{2}$ design and experimental evaluation of a large scale implementation of cool asphaltic and concrete pavements, took place. An extended monitoring was performed in the area during the summer period in its entirety. The thermal impact of the application was evaluated by means of Computational Fluid Dynamics (CFD) simulations. Simulations indicated that the use of cool non-aged asphalt can reduce the ambient temperature by up to $1.5^{\circ} \mathrm{C}$, and the maximum surface temperature by close to $11.5^{\circ} \mathrm{C}$, while the thermal comfort conditions can be strongly positively affected [15].

\subsection{The Study Objective}

The basic objective of the present study was to collect proper data for the ambient temperature and the wind speed along heavy traffic streets in the center of Athens. An additional objective of this study was to collect proper information about the thermal and optical characteristics of the materials that are used in pavements and roads in the area.

The aim of this study was the estimation of the heat island effect, based on differences of hourly air temperature values, recorded in the center of Athens and in a sub-urban station. It was estimated that during midday, the air temperature in the center of the city was up to $5^{\circ} \mathrm{C}$ higher than the corresponding one in the sub-urban station. On the contrary, early in the morning in the center of Athens near a large green area, ambient air temperature was close to $2{ }^{\circ} \mathrm{C}$ lower than the corresponding one in the reference sub-urban station. That was due to the 'negative' surface urban heat island.

Additionally, in this study a specific questionnaire depicted the unpleasantness of the city's dwellers about relevant thermal comfort conditions. Results support the application of advanced cool materials for pavements and streets, green spaces, and solar control devices in order to counterbalance the heat island phenomenon and improve the thermal comfort conditions in the city center. Studies like this provide comprehensive microclimatic data, which is of great importance for the rehabilitation of a city and the design of a sustainable urbanization to urban planners.

\section{Description of the Measuring Plan and the Monitoring Campaign}

The city of Athens is located on a basin surrounded by Penteli Mountain, $(1107 \mathrm{~m})$ in the North East, Parnitha Mountain (1426 m) in the North, Hymettus Mountain (1026 m) in the East and Egaleo Mountain (458 m) in the West. In the South of Athens' basin is the Aegean Sea. The Greater Athens basin (Figure 1) extends beyond its administrative municipal limits of Athens, with a population of 3,090,508 (over an area of $412 \mathrm{~km}^{2}$ ). According to Eurostat in 2011, the functional urban area (FUA) of Athens was the 9th most populous FUA in the European Union (the 6th most populous capital city of European Union), with a population of 3,828,000. The center of Athens had a population of 664,046 (in 2011) within its administrative limits, and a land area of $38.96 \mathrm{~km}^{2}$. Based on these data, the center of Athens is a highly dense city and measurements about UHI are of great importance.

\subsection{The Monitoring Plan}

A complete monitoring plan had been set and applied in order to depict the micro-climate conditions in the center of Athens during summer time. Measurements were performed on a continuous basis along Amalias Avenue, Panepistimiou Street and Patission Avenue in central Athens. Amalias is a major avenue with four traffic lanes, linking Panepistimiou Street with the Greek Parliament and Syntagma Square. Panepistimiou Street situates in the historical center of Athens. The total length of the street is about $1.2 \mathrm{~km}$. It consists of six lanes, five of which are for traffic and one eastbound lane for 
transit buses only. Most of the street runs almost diagonally from southeast to northwest, with the long axis in a NE-SW direction. The geometrical characteristic of the axis is not continuous. Several are the historical buildings along the street, such as the University of Athens, the Academy of Athens, the National Library, the Numismatic Museum, and the Catholic Cathedral of Athens. Many buildings as high as ten to fifteen stories line this street. Both sides of Panepistimiou Street are covered with red concrete tile pavements, while the street is covered with conventional black asphalt.

Patission Avenue is one of the major streets in Athens, connecting Omonoia Square, which is located in the center of Athens, with residential areas. It consists of four heavy traffic lanes, with the long axis in an N-S direction. The geometrical characteristic of the axis $\mathrm{H} / \mathrm{W}$ is close to 2.5. The street is covered with conventional black asphalt and the pavements are of grey tiles. Vegetation is limited across the street.

The daily experimental campaign lasted approximately nine hours (9:00LT-18:00LT). Air temperature and wind speed and direction were recorded at ten different points along the measuring route, at hourly basis. Each route lasted $60 \mathrm{~min}$ to $90 \mathrm{~min}$, depending on the traffic conditions. The measuring campaign started on the 22 May and was completed on the 17 June.

\subsection{Description of the Site}

The monitoring procedure started from Amalias Avenue. The first three measuring points were selected to be on Amalias Avenue, the entrance for the measuring route facing the North. The 1st measuring point was in front of an archaeological site. The 2nd measuring point was close to the entrance of the National Park of Athens, a widely open space with tall trees. The 3rd measuring point was in front of the Greek Parliament, an open area that covered in marble and some greenery. These measuring points were selected to be on Amalias Avenue, since they were placed on open spaces and strongly differed from the ones in the densely built Panepistimiou Street. The 4th measuring point was on Panepistimiou Street close to the intersection with Voukourestiou Street. At the specific measuring point Panepistimiou Street can be considered as an urban canyon with aspect ratio equal to two (Height/Width = 2). The following measuring point, along Panepistimiou Street, was the green area in front of the Central Historical Building of the University of Athens. The 6th measuring point—along Panepistimiou Street—was in front of a densely built block with $30 \mathrm{~m}$ height buildings, while across there was a square. No aspect ratio was estimated on the specific measuring point.

Omonoia Square is at the end of the measuring route along Panepistimiou Street. Omonoia Square is an intensive traffic area lacking greenery in the center of Athens. There was selected to be the 7th measuring point. Pavement at most spots in the square was either red or grey tiles. The measuring route continued along Patission Avenue. The thermal contribution of this area was considered to be of great importance to the thermal phenomena examined in this study. The 8th measuring point was in front of a building block ( $20 \mathrm{~m}$ height), while across was the Historical Building of the National and Technical University of Athens, which placed in an extended green area. The 9th and the 10th measuring points were along Patission Avenue. At these spots, Patission Avenue was considered as an urban canyon, with aspect ratio equal to $2.5(\mathrm{H}=25$ and $\mathrm{W}=12)$, while building blocks were from both sides. Detailed description of all the measuring points is presented in Table 1 . The survey area is presented in the two-dimensional (2D) Map of Athens basin (Figure 1). All of the measuring points are depicted in the map of the center of Athens (Figure 2). 
Table 1. The monitoring route.

\begin{tabular}{|c|c|c|c|c|c|}
\hline Measuring Point & Description & Type of Vegetation & Pavements Coating & H/W & Orientation \\
\hline M.P.1 & Amalias Avenue (shelted) & Archeological site & Red tiles & - & $40^{\circ}$ \\
\hline M.P.2 & Amalias Avenue (shelted) & National Garden of Athens & Grey tiles & - & $56^{\circ}$ \\
\hline M.P.3 & Amalias Avenue (open) & No vegetation & White Marble & - & $21^{\circ}$ \\
\hline M.P.4 & Panepistimiou Street & Few tall trees & Red tiles & $\mathrm{H} / \mathrm{W}=2$ & $297^{\circ}$ \\
\hline M.P.5 & Panepistimiou Street & Garden in the one site & Red tiles & - & $315^{\circ}$ \\
\hline M.P.6 & Panepistimiou Street & Fee tall trees & Red tiles & - & $307^{\circ}$ \\
\hline M.P.9 & Patission Avenue & Limited vegetation & Grey tiles & $\mathrm{H} / \mathrm{W}=2.5$ & $196^{\circ}$ \\
\hline M.P.10 & Patission Avenue & Limited vegetation & Grey tiles & $\mathrm{H} / \mathrm{W}=2.5$ & $196^{\circ}$ \\
\hline
\end{tabular}

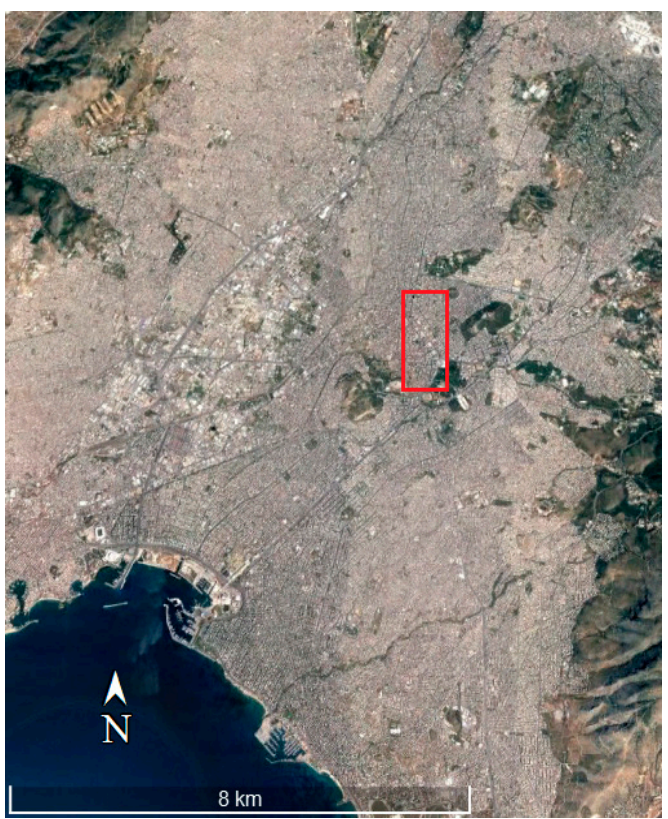

Figure 1. Survey area in GOOGLE EARTH.

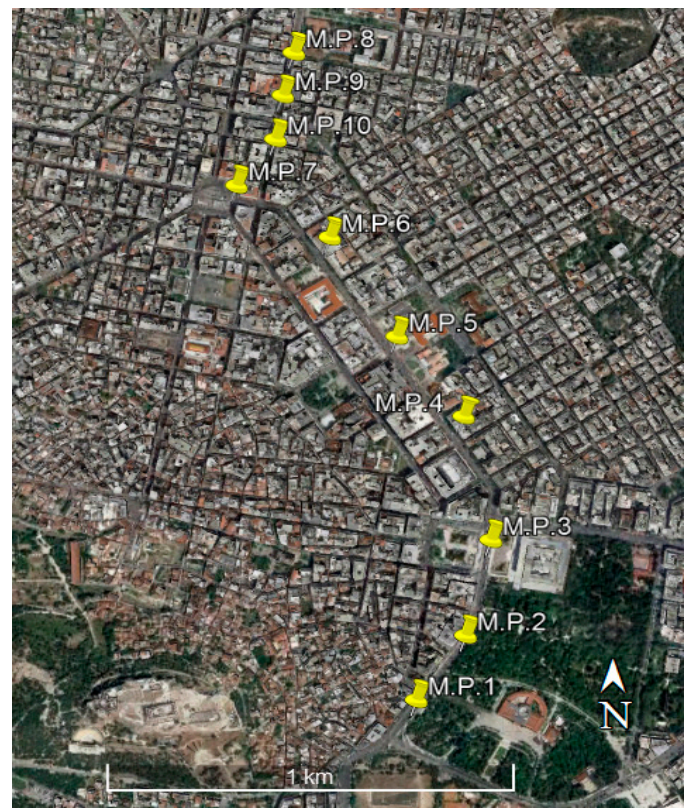

Figure 2. The measuring points in the center of Athens. 


\subsection{The Experimental Protocol}

The Mobile Meteorological Station of the University of Athens was used for the air temperature and wind speed and direction measurements. The Mobile Meteorological Station consists of: (a) a vehicle and (b) a telescopic mast PT8 Combined Collar Mast Assembly with erection height equal to $3.5 \mathrm{~m}$ and maximum head load $15 \mathrm{kgr}$. All meteorological equipment was placed on the mast at $3.5 \mathrm{~m}$ height from ground level. Measurements carried out every $30 \mathrm{~s}$. The equipment used was the following:

2.3.1. Air Temperature Miniature Thermometer (T351-PX 1/3 DIN Thermometer). The thermometers' accuracy is equal to $\pm 0.5^{\circ} \mathrm{C}$ under normal meteorological conditions and $+2{ }^{\circ} \mathrm{C}$ under low wind speed value conditions.

2.3.2. Wind Speed Anemometers (A100K Pulse Output Anemometer). The anemometers' accuracy is $\pm 0.05 \mathrm{~m} / \mathrm{s}$ with threshold value of $0.15 \mathrm{~m} / \mathrm{s}$. The operation frequency is $10 \mathrm{~Hz}$ per knot and the sampling rate of the instrument is equal to 10 pulses per 1.69 feet.

2.3.3. Wind Direction Anemometer (W200 Porton Windwane, $\pm 300^{\circ}$ Range). The accuracy of the instrument is equal to $\pm 4^{\circ}$ for wind speed greater than $3 \mathrm{~m} / \mathrm{s}$. The instruments' threshold value is equal to $0.2 \mathrm{~m} / \mathrm{s}$ with sampling analysis $15^{\circ}$.

Inside the van, data acquisition modules consisted of intelligent sensor-to-computer interface modules, which provided all of the measurements in a computer. A computer application was developed on LabVIEW engineering software, which is appropriate for the recording and the presentation of the measurements (www.ni.com).

2.3.4. On hourly basis, asphalt and pavement surface temperature, carried out for sunlit and shading conditions along the measuring path. For this purpose, an infrared thermometer equipped with a laser beam was used. The accuracy of the infrared thermometer was $\pm 0.2^{\circ} \mathrm{C}$. For more accurate measurement of the surface temperature, an infrared thermal camera was used. By means of specific software (http:/ / www.flir.eu/home), pictures of the infrared camera in visible and in infrared lead to the estimation of the accurate surface temperature in each of the measuring point according to their albedo values.

\subsection{Undisturbed Meteorological Parametrs}

The National Observatory of Athens (NOA) was preferred as reference meteorological station for this study, since it is located quite close to the measuring route. NOA is located at the top of the hill of the Nymphs a sub-urban open area close to the center of the city. The meteorological data was derived from the Environmental Research and Sustainable Development Institute measurements of the National Observatory of Athens.

\section{Discussion on the Micro-Climatic Measurements}

The climate in the city of Athens is typical 'Mediterranean', which is characterized by mild winters and dry hot summers. During the measuring procedure, an anticyclone circulation prevailed over the greater Athens basin. Anticyclone conditions favour the development of the heat island phenomenon $[7,12,14]$.

During the experimental period of this study, the wind speed measured in the reference meteorological station was up to $10 \mathrm{~m} / \mathrm{s}$ (Figure 3a). The reference meteorological station (NOA) is located at the top of the hill of the Nymphs $107 \mathrm{~m}$ from ground level. That explains the magnitude of the undisturbed wind speed values. Wind flow measured in the reference meteorological station was mainly from SW direction (Figure 3b). Simultaneously, wind speed and direction were measured in the center of the city, along the measuring path. The anemometers were placed on the telescopic mast at $3.5 \mathrm{~m}$ height from ground level. The magnitude of the wind speed values that were measured in the center of the city, during the experimental campaign, were extremely low. The $99 \%$ of the relative frequencies for the wind speed values, measured along the measuring path, were below the value of $2 \mathrm{~m} / \mathrm{s}$ (Figure 4). Due to the variance of the extremely low wind speed values, no predominated 
wind direction, in the center of the city, was estimated. This comes into to agreement with wind speed measurements in the center of Athens in a previous study [16].

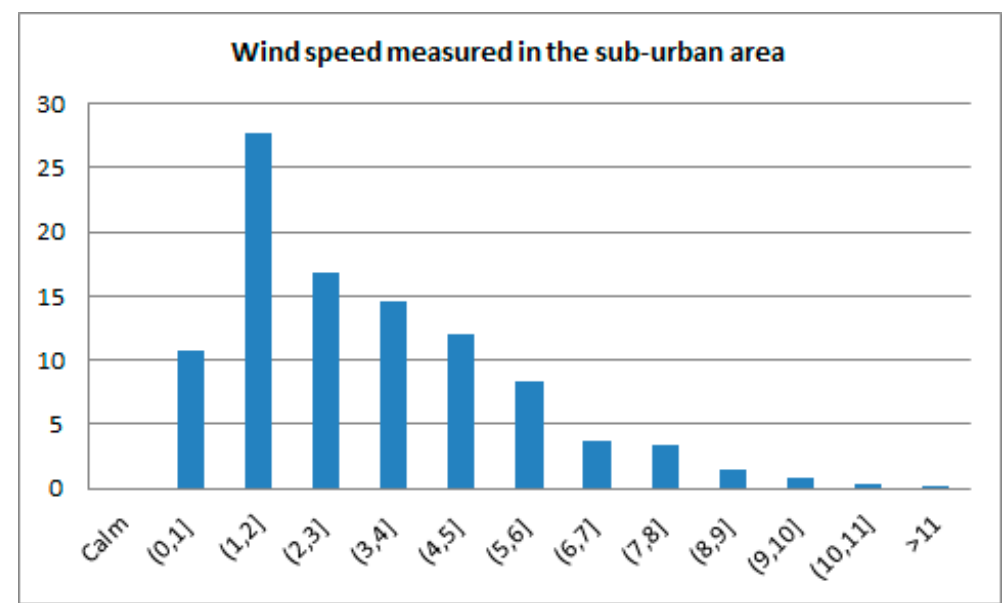

(a)

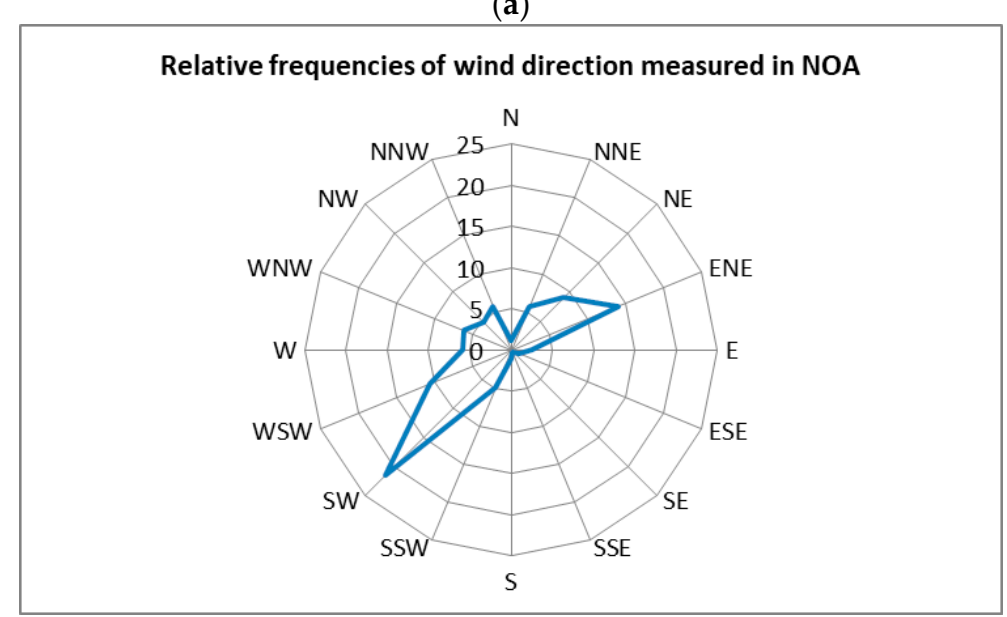

(b)

Figure 3. Relative Frequencies of the wind speed and wind direction valued recorded in National Observatory of Athens (NOA), during the experimental period.

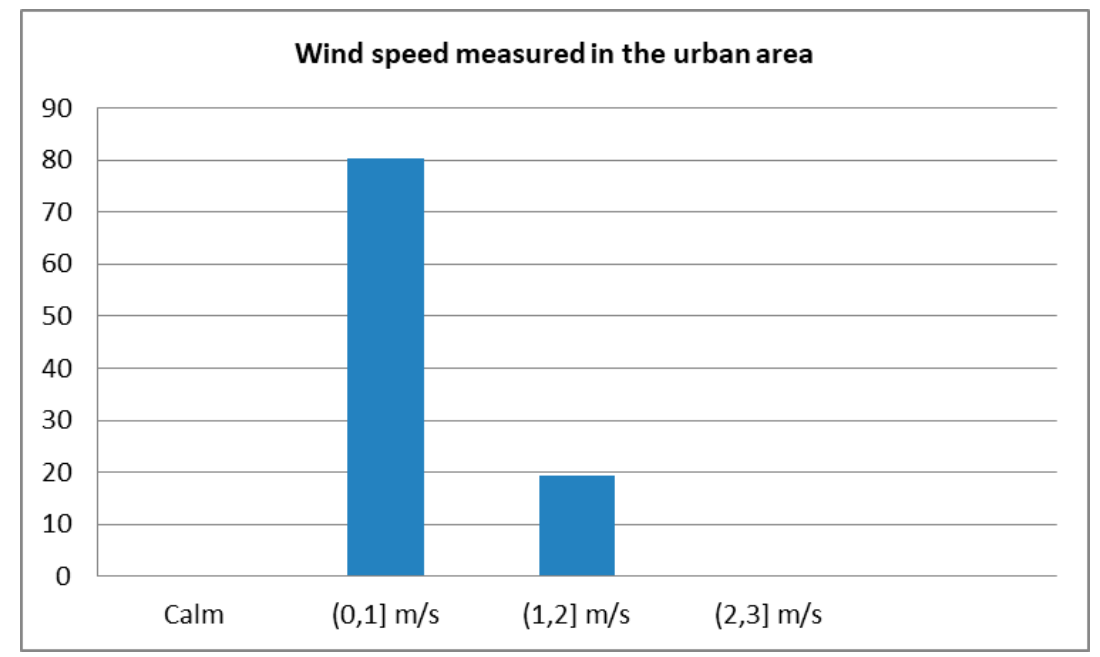

Figure 4. Relative Frequencies of the wind speed valued recorded in the center of Athens, during the experimental period. 
The experimental period lasted from 22 May up to 17 June. Early in the morning, the air temperature measured in the center of the city, close to open areas such as the National Garden of Athens (M.P.2) or in front of the Greek Parliament (M.P.3), was lower than the one that was measured in the reference meteorological station. The minimum air temperature difference between values measured in the city center and the ones that were measured in the suburban area, where the reference meteorological station was located, depicts the 'cool' surface island intensity.

In the afternoon, air temperature that was measured in the center of the city, close to Omonoia square (M.P.7) or in Patission Avenue (M.P.8) was higher than the one measured in the suburban area. The maximum air temperature difference between values measured along the measuring path, in the city center, and the one measured in the sub-urban area depicts the UHI intensity. All the measurements in UHI and the surface urban 'cool' island intensity are presented in Table 2.

Table 2. Maximum air temperature differences between urban and sub-urban measurements.

\begin{tabular}{|c|c|c|}
\hline \multirow{2}{*}{ Experimental Period } & \multicolumn{2}{|c|}{ Air Temperature Differences between Urban and Sub-Urban Area } \\
\hline & Surface Urban 'Cool’ Island Intensity & Urban Heat Island Intensity \\
\hline $\begin{array}{c}\text { 22 May: } \\
\text { 10:00LT-16:00LT }\end{array}$ & $-0.70^{\circ} \mathrm{C}$ (M.P.2) at 10:00LT & $2{ }^{\circ} \mathrm{C}$ (M.P.7) at 13:00LT \\
\hline $\begin{array}{c}\text { 24 May: } \\
\text { 9:00LT-18:00LT }\end{array}$ & $-0.89{ }^{\circ} \mathrm{C}$ (M.P.1) at 10:00LT & $\mathbf{1}^{\circ} \mathrm{C}$ (M.P.7) at 15:00LT \\
\hline $\begin{array}{c}\text { 28 May: } \\
\text { 9:00LT-16:00LT }\end{array}$ & $\mathbf{- 1 . 8 5}{ }^{\circ} \mathrm{C}$ (M.P.1) at 09:00LT & $1.52{ }^{\circ} \mathrm{C}$ (M.P.7) at 15:00LT \\
\hline $\begin{array}{c}\text { 31 May: } \\
\text { 10:00LT-17:00LT }\end{array}$ & $-0.48^{\circ} \mathrm{C}$ (M.P.4) at 10:00LT & $2.12{ }^{\circ} \mathrm{C}$ (M.P.8) at 14:00LT \\
\hline $\begin{array}{c}\text { 3 June: } \\
\text { 9:00LT-18:00LT }\end{array}$ & $-\mathbf{1 . 5 0}{ }^{\circ} \mathrm{C}$ (M.P.2) at 09:00LT & $1.23{ }^{\circ} \mathrm{C}$ (M.P.7) at 16:00LT \\
\hline $\begin{array}{c}\text { 10 June: } \\
\text { 9:00LT-16:00LT }\end{array}$ & $-0.54{ }^{\circ} \mathrm{C}$ (M.P.3) at 10:00LT & $2.12{ }^{\circ} \mathrm{C}$ (M.P.8) at 14:00LT \\
\hline $\begin{array}{c}\text { 12 June: } \\
\text { 9:00LT-14:00LT }\end{array}$ & $\mathbf{- 1 . 7 2}{ }^{\circ} \mathrm{C}$ (M.P.3) at 10:00LT & $4.5^{\circ} \mathrm{C}$ (M.P.4) at 14:00LT \\
\hline $\begin{array}{c}\text { 17 June: } \\
\text { 9:00LT-19:00LT }\end{array}$ & $-2.14{ }^{\circ} \mathrm{C}$ (M.P.3) at 10:00LT & $3.81^{\circ} \mathrm{C}$ (M.P.7) at 15:00LT \\
\hline
\end{tabular}

During the experimental period, the surface urban 'cool' intensity was always calculable. Some of the days it was less than one Celsius degree, but some others it exceed $2{ }^{\circ} \mathrm{C}$. The UHI intensity was measured always more than one Celsius degree, and reached values close to $5{ }^{\circ} \mathrm{C}$.

Representative, the UHI, and surface urban 'cool' intensity values, during 17 June are presented in Figures 5 and 6. Air temperature differences were depicted by the means of Matlab. A full grid system with two monotonically increasing grid vectors depicted all of the measuring points. The $(x, y)$ vectors referred to the real longitude and latitude of the measuring points. The limits of the temperature scale in the colorbar, in the right part of the figure, corresponded to the minimum and the maximum air temperature differences that were calculated for the total experimental period. The specific plotting permitted the observation and the thorough understanding of the temporal evolution of the air temperature in the experimental region during the experimental campaign.

Regarding the heat island intensity, an important parameter is related to the thermal properties of the materials that the area is composed of. For this reason, the surface temperature of paving and asphalt was measured on hourly basis during the experimental campaign. As representative for the whole experimental period, the 3 and the 17 June were selected. These were the days that the lowest and the highest air temperatures recorded, both in the center of Athens and the reference meteorological station. On the 'cool' day of the experimental period (3 June), the differences of the mean surface temperature between the sunlit and the shaded asphalt were close to $16{ }^{\circ} \mathrm{C}$. For the presentation of the surface temperature differences, the whisker chart was used, which was based on the boxplot analysis of the measurements (Figure 7). It is of great importance that the magnitude of the differences 
between the sunlit and the shaded asphalt on 17 June the 'warmest' day of the experimental period was exactly of the same magnitude (Figure 8). It seems that the degraded asphalt contributes a specific amount of energy to the air above due to the very low albedo, regardless the day. The albedo of the degraded asphalt, used in the center of Athens, was measured close to 0.04 [17].

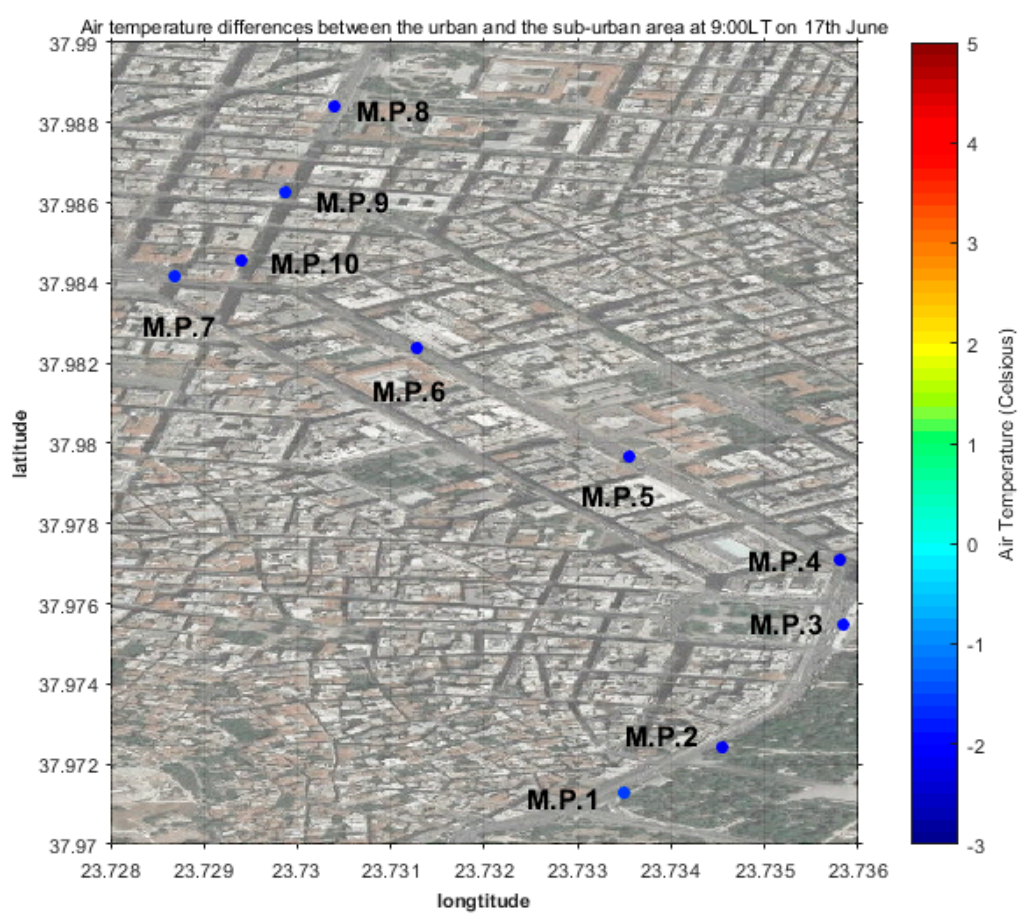

Figure 5. Air temperature differences between the ones recorded in the center of Athens at 9:00LT and the ones in the suburban station, during the 17 June.

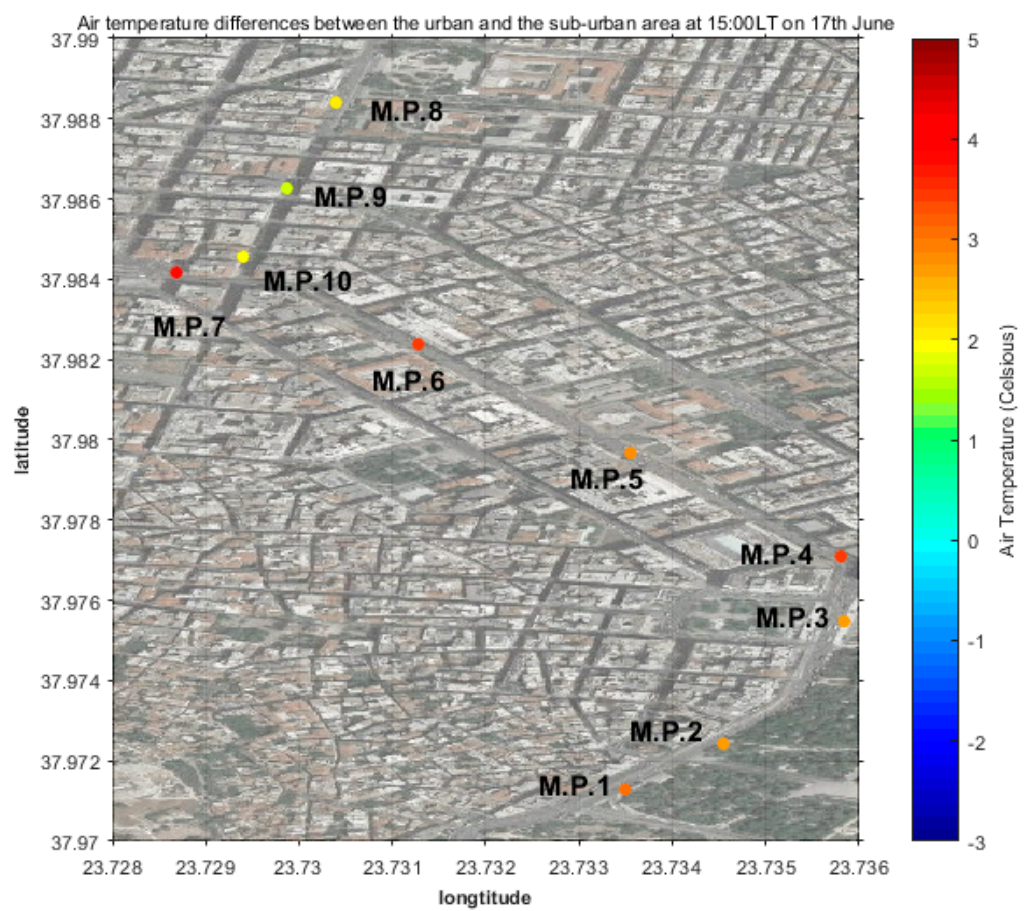

Figure 6. Air temperature differences between the ones recorded in the center of Athens at 15:00LT and the ones in the suburban station, during the 17 June. 


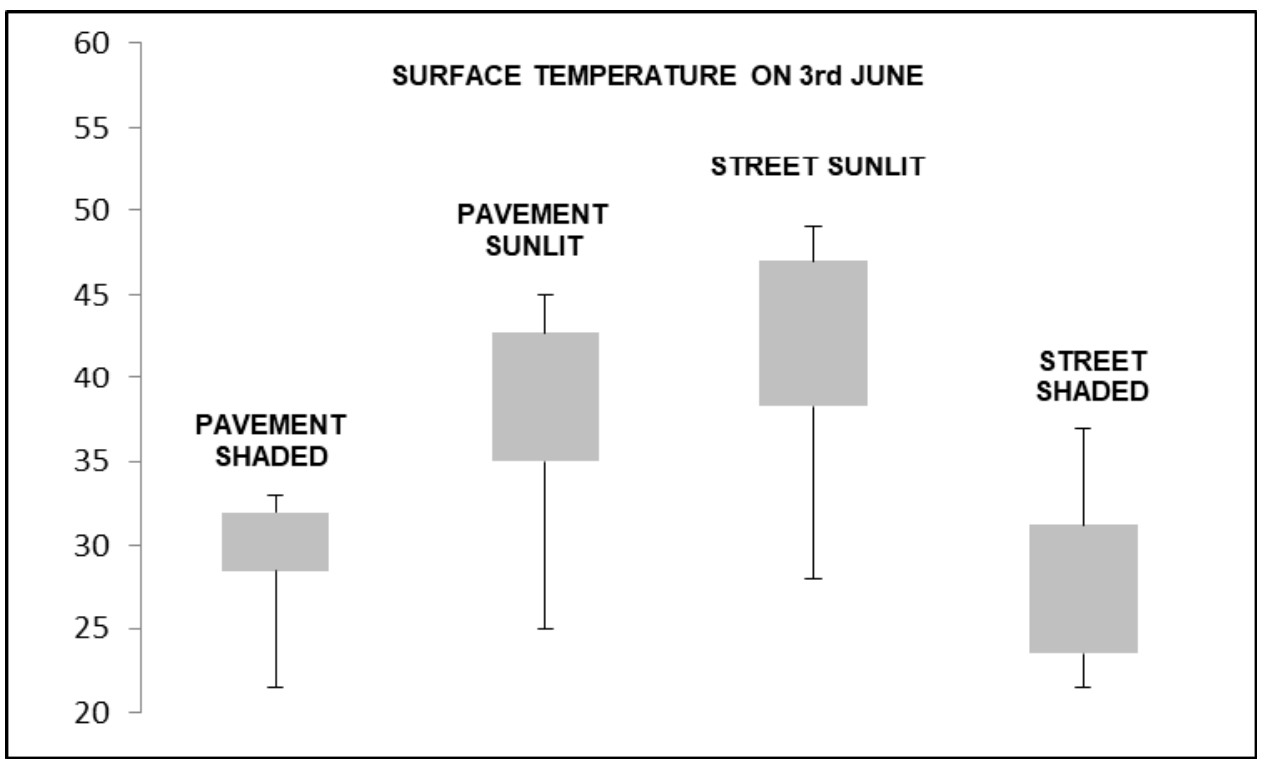

Figure 7. Surface temperature measured on sunlit and shaded pavement/asphalt/on the 3 June.

The maximum surface temperature differences between sunlit and shaded pavement were $8{ }^{\circ} \mathrm{C}$ during the 'cool' day and $12{ }^{\circ} \mathrm{C}$ during the 'warmest' day of the experimental period (Figures 7 and 8). The albedo of the dark paving materials was measured close to 0.22 , which is five times higher than the one measured for asphalt [17]. Due to that, the surface differences for pavement are lower than the one measured for asphalt. Another important parameter is that the hourly surface temperature for pavement is strongly connected to the measuring point where measurement was held.

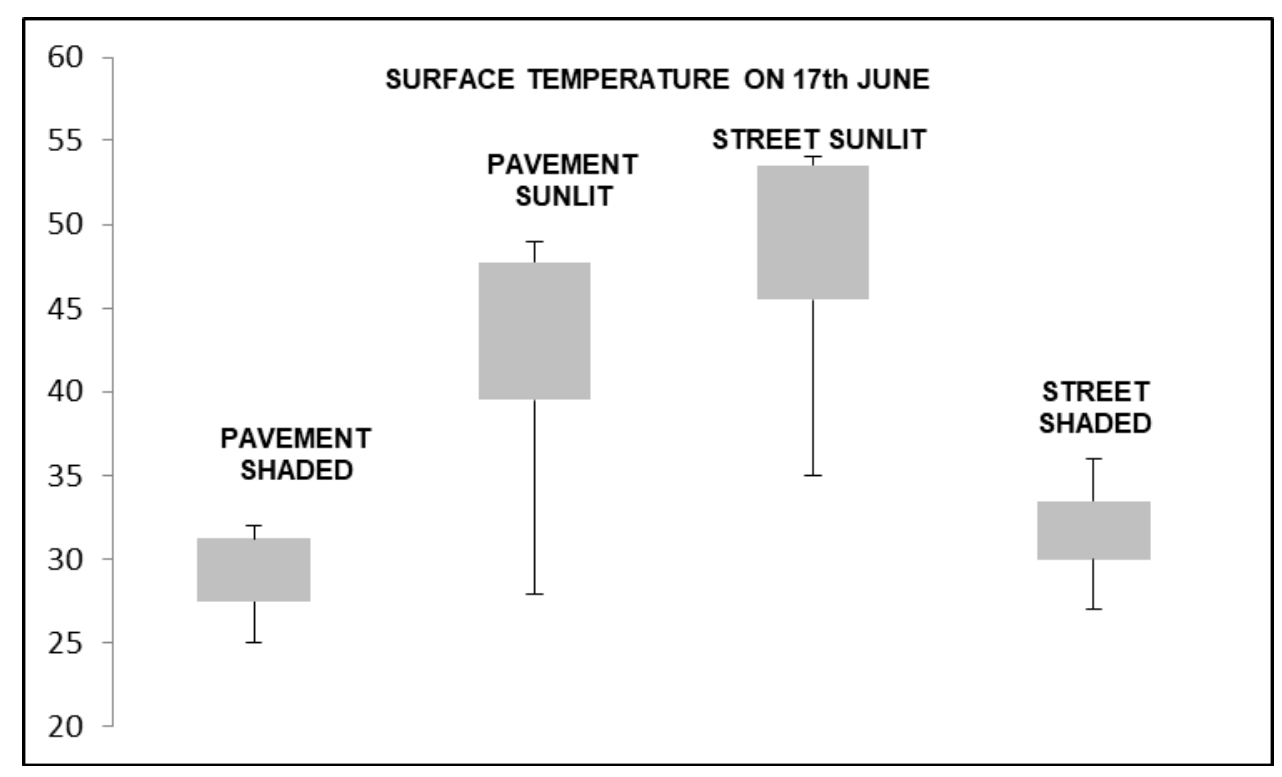

Figure 8. Surface temperature measured on sunlit and shaded pavement/asphalt/on the 17 June.

\section{Pedestrians Estimation on Thermal Comfort Conditions in the Measuring Area}

The existence of the urban heat island, because of the high urban temperatures, has a great impact to the quality of living in the city. People living in the densely built center of the city usually feel unpleasant because of the high summer air temperature situation. In the worst cases, it was referred that urban warming is increasing the number of hospital admissions [18]. 
Part of the experimental procedure was the distribution of a questionnaire that was related to the thermal comfort conditions, along the experimental path, in specific measuring points. Questionnaires were distributed to pedestrians in the National Garden of Athens (M.P.2), in Syntagma Square (M.P.3), Voukourestiou Street (M.P.5), and in Omonoia Square (M.P.7). In these questionnaires, pedestrians expressed their opinion on the experienced thermal conditions, the weather conditions and the street set-up.

The dissatisfaction was obvious on how pedestrians felt in Omonoia Square (M.P.7), which has no shading and the vegetation is limited when compared to the rest of the measuring points. The city dwellers around Omonoia Square had a completely negative opinion about the environmental quality. Apparent was the unpleasantness regarding temperature and solar radiation levels in the measuring point. At the same time, the questioned were dissatisfied with the quality of the materials that were used in Omonoia Square. Air pollution, noise pollution, and anthropogenic heat increased the unpleasantness levels of the people asked. Based on the answers that were given, the thermal discomfort feeling increased gradually from National Park area (M.P.1) up to Omonoia square in the center of Athens (M.P.7).

\section{Main Conclusions and Suggestions}

The aim of this study was to analyze and understand the thermal behavior of the city center of Athens. Based on the analysis of the micro-climatic measurements, the following conclusions were derived:

$>$ The air temperature in the monitored zone presented important differences when compared to the undisturbed air temperature recorded in reference station in the National Observatory of Athens.

$>$ Based on measurements of this study, during the morning hours, air temperature measured in the densely built area close to green areas was lower up to $2{ }^{\circ} \mathrm{C}$ than the ones that were measured at the reference meteorological station. The magnitude of the surface 'cool' island reached up to $2{ }^{\circ} \mathrm{C}$, proving the great influence that greenery has on air temperature distribution within the city. This comes into agreement with a relative previous study $[13,19,20]$.

$>$ In the afternoon, the warmest parts of the monitoring area in the city center presented up to $5{ }^{\circ} \mathrm{C}$ higher temperatures than the ones measured in the reference meteorological station. The UHI intensity measured in this study was up to $5{ }^{\circ} \mathrm{C}$ and come with agreement with measurements of previous studies [6-8].

$>$ The daily air temperature variance along the monitoring route, between the warmest and the coolest zones of the city center, varied from $5{ }^{\circ} \mathrm{C}$ up to $8{ }^{\circ} \mathrm{C}$. The temperature variation strongly depended on the current meteorological conditions. This comes into agreement with the results of a previous study, where maximum air temperature differences between the most central urban stations to the rural ones were up to $10{ }^{\circ} \mathrm{C}$ during daytime [8].

$>$ The highest ambient temperature was recorded in the most central measuring points (M.P.7 and M.P.8). This was mainly due to the increased thermal balance of the city's center. The anthropogenic heat released in the city's center, the lack of solar control, the lack of vegetation, and the type of materials used for the coating of pavements, contributed to enhancing the heat island effect.

$>$ Huge was the contribution of the unsuitable pavement coatings and the degraded asphalt into the air temperature distribution in the center of Athens. Differences between sunlit and shaded parts of the asphalt was stable, regardless the day, and were measured close to $16^{\circ} \mathrm{C}$. Differences between sunlit and shaded pavements varied from $8{ }^{\circ} \mathrm{C}$ up to $12{ }^{\circ} \mathrm{C}$. The existence of the materials presenting very high absorptivity, together with the very high thermal capacitance, increases the storage capacity of the monitoring area in the center of Athens and keeps air temperature in high levels for longer periods. 
$>$ As it was expected, wind speed and direction values within the city strongly differed from measurements in the suburban meteorological station. The lower wind speed values measured in the center of the city are a fact that increases the intensity of the heat island $[10,16]$.

\section{General Comments}

Microclimatic conditions in the urban fabric are mainly influenced by the geometry of the built area, the greenery, and the optical and thermal properties of the materials that are used as coatings of the buildings. The local micro-climate was affected, as expected, by the morphology of the urban pattern (orientation of the measuring points; aspect ratio of the street). The most important factors for the existence of the heat island were vegetation/shading factors and the thermal impact of the surrounding surfaces. Higher air temperature values were recorded during midday, due to the urban heat island, possibly caused from the heavy traffic, the increased anthropogenic heat in the center of the city, and the lack of green spaces.

The positive effect of vegetation on the UHI is obvious, at least during the morning hours. That proves the importance of green spaces, since in the morning the evapotranspiration cooling mechanisms of a big green urban area (like the National Garden of Athens) reduce air temperature up to $2{ }^{\circ} \mathrm{C}$ when compared to the surrounding parts of the city. After midday, air temperature in the center of a city increases dramatically, reaching values up to $5{ }^{\circ} \mathrm{C}$ higher than air temperature in the suburban area. That means that the air temperature daily distribution increases abruptly. The contribution of the unsuitable pavement coatings and the asphalt into the air temperature distribution in the surrounding area is of great importance. Surface temperature differences between sunlit versus shaded asphalt measured close to $16^{\circ} \mathrm{C}$. This study can assist architects of outdoor spaces, building physicists, and engineers to improve the urban thermal behavior by means of cool materials. Additionally, the increase of urban greenery as a solar control technique is important on the regulation of the ambient temperature in a highly dense area, like the city of Athens.

Acknowledgments: Thanks are due to Institute for Environmental Research and Sustainable Development, of the National Observatory of Athens, for the permission to use meteorological data for the aims of this study.

Author Contributions: Chrissa Georgakis and Mattheos Santamouris contributed to the design and implementation of the experimental procedure, to the analysis of the measurements and to the writing of the manuscript.

Conflicts of Interest: The authors declare no conflict of interest.

\section{References}

1. Oke, T.R. Boundary Layer Climates, 2nd ed.; Routledge: London, UK; New York, NY, USA, 1987.

2. Akbari, H.; Cartalis, C.; Kolokotsa, D.; Muscio, A.; Pisello, A.; Rossi, F.; Santamouris, M.; Synnefa, A.; Wong, N.; Zinzi, M. Local Climate Change and Urban Heat Island Mitigation Techniques-The State of the Art. J. Civ. Eng. Manag. 2015, 22, 1-16. [CrossRef]

3. Santamouris, M. Heat island research in Europe-state of the art. Adv. Build. Energy Res. 2007, 1, $123-150$. [CrossRef]

4. Santamouris, M.; Cartalis, C.; Synnefa, A. Local urban warming, possible impacts and a resilience plan to climate change for the historical center of Athens, Greece. Sustain. Cities Soc. 2015, 19, 281-291. [CrossRef]

5. Catsoulis, B.D.; Theoharatos, G.A. Indications of urban heat island in Athens, Greece. J. Clim. Appl. Meteorol. 1985, 24, 1296-1302. [CrossRef]

6. Kassomenos, P.A.; Katsoulis, B.D. Mesoscale and macroscale aspects of the morning urban heat island around Athens, Greece. Meteorol. Atmos. Phys. 2006, 94, 209-218. [CrossRef]

7. Mihalakakou, G.; Santamouris, M.; Papanikolaou, N.; Cartalis, C.; Tsangrassoulis, A. Simulation of the urban heat island phenomenon in Mediterranean cli-mates. J. Pure Appl. Geophys. 2004, 161, 429-451. [CrossRef]

8. Santamouris, M.; Papanikolaou, N.; Livada, I.; Koronakis, I.; Georgakis, C.; Argiriou, A.; Assimakopoulos, D.N. On the impact of urban climate on the energy consumption of buildings. Sol. Energy 2001, 70, 201-216. [CrossRef] 
9. Giannopolulou, K.; Santamouris, M.; Livada, I.; Georgakis, C.; Caouris, Y. The Impact of Canyon Geometry on Intra Urban and Urban: Suburban Night Temperature Differences Under Warm Weather Conditions. J. Pure Appl. Geophys. 2010, 167, 1433-1449. [CrossRef]

10. Gaitani, N.; Santamouris, M.; Cartalis, C.; Pappas, I.; Xyrafic, F.; Mastrapostoli, E.; Karahaliou, P.; Efthymiou, C. Microclimatic analysis as a prerequisite for sustainable urbanisation: Application for an urban regeneration project for a medium size city in the greater urban agglomeration of Athens, Greece. Sustain. Cities Soc. 2014, 13, 230-236. [CrossRef]

11. Santamouris, M.; Synnefa, A.; Karlessi, T. Using advanced cool materials in the urban built environment to mitigate heat islands and improve thermal comfort conditions. Sol. Energy 2011, 85, 3085-3102. [CrossRef]

12. Santamouris, M.; Gaitani, N.; Spanou, A.; Saliari, M.; Giannopoulou, K.; Vassilakopoulou, K.; Kardomateas, T. Using cool paving materials to improve microclimate of urban areas-Design realization and results of the flisvos project. Build. Environ. 2012, 53, 128-136. [CrossRef]

13. Santamouris, M. Cooling the cities-A review of reflective and green roof mitigation technologies to fight heat island and improve comfort in urban environments. Sol. Energy 2014, 103, 682-703. [CrossRef]

14. Santamouris, M.; Xirafi, F.; Gaitani, N.; Spanou, A.; Saliari, M.; Vassilakopoulou, K. Improving the Microclimate in a Dense Urban Area Using Experimental and Theoretical Techniques-The Case of Marousi, Athens. Int. J. Vent. 2012, 11, 1-16. [CrossRef]

15. Kyriakodis, G.E.; Santamouris, M. Using reflective pavements to mitigate urban heat island in warm climates-Results from a large scale urban mitigation project. Urban Clim. 2017, in press. [CrossRef]

16. Georgakis, C.; Santamouris, M. Experimental investigation of air flow and temperature stratification in deep urban canyons for natural ventilation purposes. Energy Build. 2006, 38, 367-376. [CrossRef]

17. Lontorfos, V.; Efthymiou, C.; Santamouris, M. On the Time Varying Mitigation Performance of Reflective Geoengineering Technologies in Cities. Renew. Energy 2017, in press. [CrossRef]

18. Santamouris, M.; Kolokotsa, D. On the impact of urban overheating and extreme climatic conditions on housing energy comfort and environmental quality of vulnerable population in Europe. Energy Build. 2015, 98, 125-133. [CrossRef]

19. Kolokotroni, M.; Giridharan, R. Urban heat island intensity in London: An investigation of the impact of physical characteristics on changes in outdoor air temperature during summer. Sol. Energy 2008, 82, 986-998. [CrossRef]

20. Stathopoulou, M.; Synnefa, A.; Cartalis, C.; Santamouris, M.; Karlessi, T.; Akbari, H. A surface heat island study of Athens using high solution satellite imagery and measurements of the optical and thermal properties of commonly used building and paving materials. Int. J. Sustain. Energy 2009, 28, 59-76. [CrossRef] 